\title{
A REVIEW BASED ON CHANNEL ESTIMATION FOR OPTICAL - ORTHOGONAL FREQUENCY DIVISION MULTIPLEXING
}

\author{
Nisha Mary Joseph \\ Department of Electronics and Communication Engineering, \\ Dayananda Sagar University, Bangalore, India \\ Dr. Puttamadappa C. \\ Department of Electronics and Communication Engineering, \\ Dayananda Sagar University, Bangalore, India
}

\begin{abstract}
Optical - Orthogonal Frequency Division Multiplexing (OFDM) system generally employ in several communication devices such as telephone, radio, television, internet and so on. In the present days, the optical OFDM is one of the significant methods for an effective communication system. In communication technique, the channel estimation plays a major role in finding the characteristics of the channel based on the received data value. In order to manage the communication data, most of the researchers focused on the channel estimation by using different techniques like Minimum Mean Square (MMSE), Least Square, blind, semi-blind and also developed new methodologies in the coherent optical OFDM. This review paper analysed the research works based on the channel estimation algorithms of an optical OFDM and also examined the major limitation of these techniques. This paper will help the researchers to give a better solution for the present drawbacks in the coherent optical OFDM system.
\end{abstract}

Keywords: Channel estimation, Genetic algorithm, Optical-orthogonal frequency division multiplexing, Visible light communication.

Cite this Article: Nisha Mary Joseph and Dr. Puttamadappa C, A Review Based on Channel Estimation for Optical - Orthogonal Frequency Division Multiplexing, International Journal of Electrical Engineering \& Technology, 10(2), 2019, pp. 48-56. http://iaeme.com/Home/issue/IJEET?Volume=10\&Issue=2

\section{INTRODUCTION}

The optical OFDM is a multicarrier transmission technique that transmit the data with lowrate subcarrier tones. OFDM has been significantly studied in the mobile communication to combat the hostile frequency selective fading and incorporated into wireless communication standards (HiperLAN2, 802.16 WiMAX digital audio and video broadcasting (DVB-T, and DAB) in Europe, and Australia [1]. Presently, an equivalent optical-domain multi-carrier 
format known as coherent OFDM [2], considered as a promising technique for long-haul optical communication systems due to its more spectral efficiency and robustness against polarization mode dispersion and chromatic dispersion [3], [4]. However, the long symbol period of the coherent OFDM is sensitive to laser phase noise. The laser phase noise generates the both inter-carrier interference and Common Phase Error (CPE), which reduces the performance of the system. Hence, it is significant to estimate and compensate the CPE [5]. Several research work carried out for enhancing the efficiency of optical channel estimation of coherent OFDM, but still these methods not able to achieve satisfactory results in retrieval performance. In recent years, researcher used different techniques to compensate the CPE in OFDM system. The conventional compensation techniques are 2-types: analog techniques based on Radio Frequency (RF) pilots and digital technique based on pilot subcarriers.

The RF pilot technique has achieved less spectral efficiency due to frequency guard band and power overheads. The pilot subcarrier does not require more overhead, but it needs time to coverage and commonly has the cycle slip problem, which degrades the laser phase tolerance [6]. The channel estimation is used for block type pilot arrangement based on MMSE or LS channel estimation techniques. The MMSE based channel estimation produce 10 to $15 \mathrm{~dB}$ gain in signal to noise ratio for the same Mean Square Error (MSE) of channel estimation over LS estimate [7]. A low-rank approximation applies to the linear MMSE by employing frequency correlation of the channel to neglect the major limitation of the MMSE technique, which is more complex [8]. Optical line components like coupler, switch, erbiumdoped fiber amplifier, and isolator gets affected by the Polarization Mode Dispersion (PMD) which causes a non-negligible error in the optical OFDM. System performances affect by various parameters such as, Optical Signal to Noise Ratio (OSNR), Bit Error Rate (BER) and MSE. There are several re-portable approach is used to estimate the common section error in optical OFDM system [9] [10]. In optical OFDM system, channel estimation is the most important aspect of retrieval technology and also the correlation are measured to increase an efficiency of the research process to the optical OFDM system. In this paper, a detailed review on the channel estimation for optical-OFDM has done in order to analyse the performance and problems of the existing technologies. This process motivates the researchers for further research work in channel estimation technique for optical OFDM.

\section{OVERVIEW OF THE CHANNEL ESTIMATION FOR OPTICAL OFDM}

Channel estimation techniques commonly categorize as semi-blind, blind, Pilot Aided (PA) channel estimations. The blind channel estimation performs by utilizing the statistics of received data, virtual carriers, cyclic prefix, and received diversity. That blind estimations commonly require the channel to be constant for a huge number of blocks. So, the blind channel estimation approach is not suitable for large mobility applications. The topmost communication standards such as Long-Term Evaluations (LTEs) and digital video broadcasting has increased the system efficiency by using the pilot channel estimation techniques. In large mobility channel estimation, each stage has individual challenges and features due to a long time dispersion, and the fast time-variation of the channels [11].

\subsection{General procedure for the Channel Estimation}

Presently most of the communication systems require channel estimation for symbol detection and equalization process. It improves by employing dedicated pilot symbol, which consumes a non-negligible part of power resources and throughput for huge dimensional device/system. The LS approach based channel estimation technique is most suitable for other optical OFDM systems. The physical Visible Light Communication (VLC) channel scheme includes diffuse 
elements and line of sight (LOS) [12]. The channel impulse response from the $i^{\text {th }}$ Light Emitting Diode (LED) to the $k^{\text {th }}$ user is expressed in Eq. (1),

$$
c_{(k, i)}(t)=\eta(k, i) \cdot \operatorname{LOS} \delta(t)+c_{(k, i)}, \text { diffuse }\left(t-\nabla_{\tau}(k, i)\right)
$$

Here, $\eta(k, i) L O S$ represents the LOS elements, $i^{\text {th }}$ is Dirac delta function, $c_{(k, i)}$, diffuse is diffusion element, $\nabla_{\tau}(k, i)$ represents delay between the diffuse and LOS signal. In discrete time domain, the channel impulse signal from the $i^{\text {th }}$ LED to $k^{\text {th }}$ user is shown in Eq. (2),

$$
h_{(k, i)}(n) \stackrel{\Delta}{=} c_{(k, i)}\left(n T_{S}\right)
$$

Where, $T_{S}$ represents the sampling interval. In the intensity modulation of DD VLC [13], the signal fed to LEDs must be real and non-negative. Thus, the signal or tone in the frequency domain of $i^{\text {th }}$ LED must be Hermitian symmetric as represented in Eq. (3),

$$
\left\{\begin{array}{l}
x_{i}(K)=X_{i}^{*}(N-K) \\
X_{i}(0)=X_{i}\left(\frac{N}{2}\right)=0
\end{array}\right\}
$$

Here, $N$ represents total number of sub-carriers. The received signal of $k^{\text {th }}$ user is expressed in Eq. (4),

$$
y_{k}(n)=\sum_{i=1}^{N_{t}} h_{(k . i)}(n) \otimes\left(x_{i}(n)+D C_{i}\right)+\omega_{k}(n)
$$

Where, $x_{i}(n)$ is the Time domain expression of $X_{i}(K), \otimes$ standard convolution, $D C_{i}$ represents DC bias added at the $i^{\text {th }} \mathrm{LED}, \omega_{k}(n)$ denotes the noise component at the receiver of $k^{\text {th }}$ user. Next deleting the cyclic prefix, then taking Fast Fourier Transform (FFT) of $y_{k}(n)$, the frequency domain signal is expressed in Eq. (5),

$$
y_{k}(K)=\sum_{i=1}^{N_{i}} H_{(k . i)}(K) X_{i}(K)+W_{k}(K) \quad K>0
$$

Here, $H_{(k, i)}=F F T\left\{h_{(k, i)}(n)\right\}, W_{k}(K)=F F T\left\{\omega_{k}(n)\right\}$, and FFT \{.\} represents FFT operation. The signal $y_{k}(K)$ can be rewrite in the vector form is expressed in Eq. (6)

$$
y_{k}=\sum_{i=1}^{N_{i}} \operatorname{diag}\left\{X_{I}\right\} F h_{(k, i)}+W_{k}
$$

Here, $\quad y_{k}=\left[Y_{k}(1), Y_{k}(2), \ldots \ldots \ldots Y_{k}(N-1)\right]^{T}, \quad T$ denotes the transpose operation. $X_{i}=\left[X_{i}(1), X_{i}(2), \ldots \ldots \ldots X_{i}(N-1)\right]^{T}, \quad \operatorname{diag}\{$.$\} \quad represents diagonal operation,$ $H_{(k, i)}=\left[H_{(k, i)}(1), H_{(k, i)}(2), \ldots \ldots \ldots H_{(k, i)}(N-1)\right]^{T}$, and $\quad W_{i}=\left[W_{i}(1), W_{i}(2), \ldots \ldots \ldots . W_{i}(N-1)\right]^{T}$, $h_{(k, i)}=\left[h_{(k, i)}(1), h_{(k, i)}(2), \ldots \ldots \ldots . . . h_{(k, i)}(L-1)\right]^{T}$, here $L$ - represents length of the channel, $F$ - denotes the first $L$ columns of the FFT T-matrix except the first row, which assume $N_{P}$ pilot tones for the channel estimation. A pilot tone indices are similar for all transmit LED. Describe a set of pilot tone indices expressed in Eq. (7),

$$
Z_{p}=\left\{k_{0}+l \cdot N_{I}, l=0,1,2, \ldots N_{P} / 2-1\right\}
$$

Here, $k_{0} \in\left\{1, \ldots . N_{I}-1\right\}$ represents the first pilot tone position, $N_{I}$ denotes pilot tone interval period of the $Z_{P}$. To satisfy Hermitian scheme, the group of pilot tone indices in DC biased optical OFDM based on VLC is defined in Eq. (8), 
A Review Based on Channel Estimation for Optical - Orthogonal Frequency Division Multiplexing

$$
\Omega_{P}=\left\{K / K \in Z_{P}\right\}
$$

In OFDM pilot symbol, the pilots occupy the specific subcarriers that include pilot tones, and other sub-carriers can be employed to Carry Information Data (CID), it will degrade the power of received signal. Next, the channel estimation of every user will be sent back to a transmitter used for Zero Forcing (ZF) pre-coding. Hence, it is expected that the OFDM pilot symbol will only carry pilots, no data will be carried in the OFDM pilot symbol. Example for the channel estimation is given in Eq. (9),

$$
\begin{array}{r}
Y_{k}^{(p)}=\sum_{I=1}^{N_{i}} \operatorname{diag}\left\{P_{I}\right\} H_{(k, i)}^{P}+H_{(k, i)}^{p} \\
Y_{k}^{(p)}=\sum_{I=1}^{N_{i}} A_{i} E h_{(k, i)}+W_{K}^{(P)}
\end{array}
$$

Here, $P_{i} \quad$ represents pilot order vector of $i^{\text {th }} \mathrm{LED}, A_{i}=\operatorname{diag}\left\{P_{i}\right\}, H_{(k, i)}^{p}$ are represents channel vector, noise vector to pilot tone. $E$ Contains rows of $F$.

\subsection{Data-Aided Channel Estimation (D-ACE)}

The fig. 1 shows the diagram of common pilot symbols and pilot subcarriers sequence. The DACE technique send the pilot sequence to the preamble of each data set, and apply to the various kinds of channels, even though the pilots degrades the data ratio. One of the channel estimation technique done by employing pilot symbols as a reference signal. The pilot symbols do not carry information, but it is known in both transmitter and receiver.
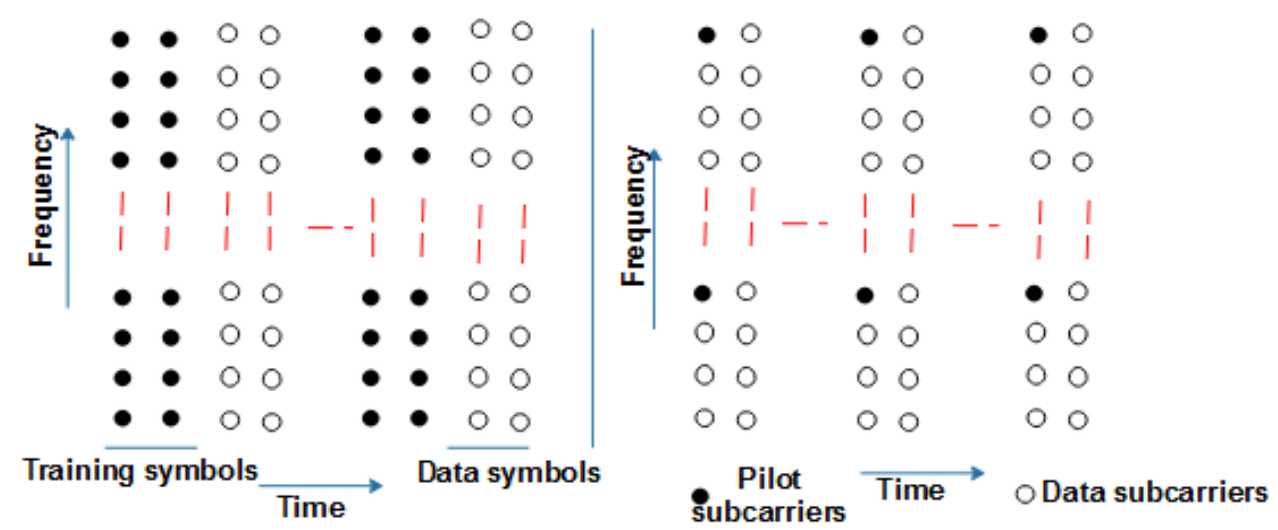

Figure 1 Diagram of common pilot symbols and pilot subcarriers sequence

The characteristic of the estimated channel technique to the real value offers a better reference signal to create an equalization at the receiver. In the D-ACE technique, known information to receiver is inserted in the optical OFDM symbol so that current channel can be estimated. The previous data arrangement is known as channel estimation. That channel estimation with training symbols is called as Pilot-Aided Channel Estimation (PACE).

\subsubsection{Pilot based channel estimation}

In the pilot based estimation technique, the training symbols known to the receiver is multiplexed with the data stream. The pilot channel estimation method uses an idea of the transmitted pilot symbols at the receiver to estimate the channel. The extra pilot symbol with the particular pilot pattern employ for the channel estimation, which is called as pilot based channel estimation. 

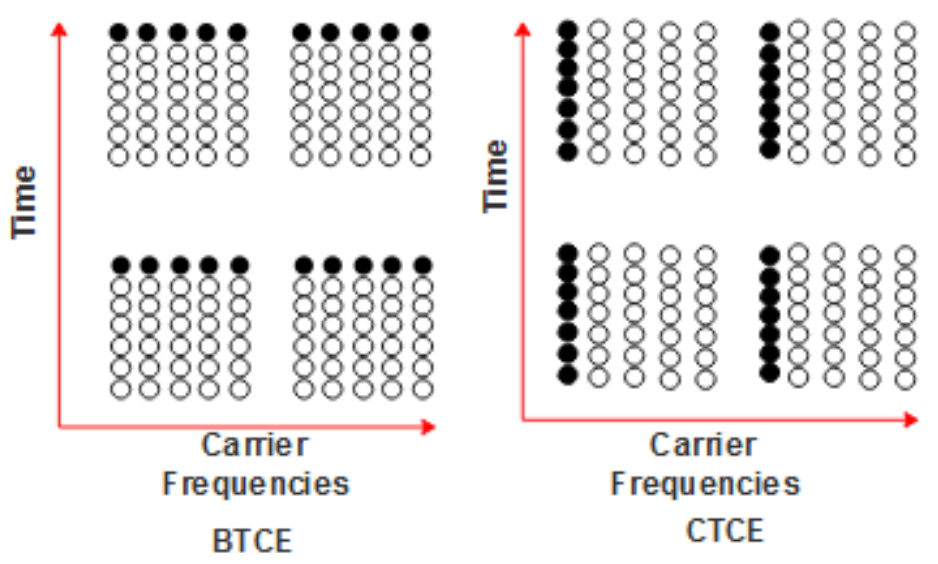

Figure 2 Diagram of pilot based channel estimation technique like BTCE, and CTCE method

The pilot based channel estimation is classified into two types Block Type Channel Estimation (BTCE) and Comb Type Channel Estimation (CTCE). In the BTCE technique, training symbols insert into whole frequency bins with periodic time of the optical OFDM blocks, which suits for a slow fading channel. The CTCE technique is used for the fast fading channel where the channels changes between adjacent optical OFDM, the pilots are transmitted at all times with similar spacing on the subcarrier representing a CTCE placement. The fig. 2 shows the diagram of PTCE and CTCE technique based pilot arrangement.

\subsection{Training based LS Channel Estimation (LSCE)}

The training symbols are used for the channel estimation which provides a better performance. But, their transmission effectiveness is mitigated due to needed overhead of training symbols like pilot tones. The LS and MMSE approaches mostly use for channel estimation when training symbols are available.

\subsubsection{LS Channel Estimation (LSCE)}

The LSCE technique utilizes a number of statistical data in the Channel Frequency Response (CFR). In white Gaussian noise, it is easy to deliver the LS estimation value which is equivalent to the Maximum Likelihood (ML) estimation. For traditional channel estimation issue, the ML channel estimation is the optical technique that improves the Cramer Rao Bound (CRB) performance. Since ML estimation approach requires an idea about the channel statistics, because the estimation performances are not better. Moreover, the LSCE technique may affect noise enhancement when the channel matrix has a huge condition number. Channel estimate $\hat{H}$ in the LSCE technique is described by the Eq. (10),

$$
\hat{H}_{L S C E}[K]=\frac{A[K]}{B[K]}
$$

The MSE of LSCE is given as

$$
\hat{M S E}_{L S C E}=\frac{\sigma^{2} c}{\sigma^{2} c}
$$

From Eq. (11), MSE is inversely proportional to signal to noise ratio, which may be subject to noise enhancement, when the channel is in a deep null due to its simplicity. However, the LSCE technique has been generally employed for the channel estimation [14].

\subsubsection{Training based MMSE channel estimation}

Consider the LSCE technique solution in Eq. (10). By employing the weight matrix $W$, it is defined as $\hat{H}=W \tilde{H}$, which corresponds to MMSE channel estimate as shown in Eq. (12), 
A Review Based on Channel Estimation for Optical - Orthogonal Frequency Division Multiplexing

$$
\hat{H}=W \tilde{H}=R_{\tilde{H} H} R_{\tilde{H} \tilde{H}}^{-1} \tilde{H}
$$

Here, $R_{H \tilde{H}}$ is the cross channel matrix function between the temporary channel and true channel vector in the frequency domain [15].

\subsection{Blind Channel Estimation (BCE)}

The BCE technique use the statistical data of received symbols [16]. The major advantage of BCE is that it consumes high-level bandwidth, but it limited to slow time-varying channels, and more complex at the receiver. The training arrangement not require in the blind technique. The BCE approaches are two types statistical estimation, and deterministic estimation. The statistical estimation employs an orthogonal between the noise and channel subspace vector, it is known as sub-space technique. Thus, the Eigenvalue decomposition of an auto-correlation matrix of the received signal require in the BCE algorithm in order to find the noise subspace matrix. On the other hand, the deterministic technique employs the property of the limited alphabet to the symbol, which converges faster compared to the statistical technique. The main limitation of BCE technique is that it is more complex in the transceiver [17].

\subsection{Semi- Blind Channel Estimation (S-BCE)}

The S-BCE technique is the hybrid combination of data aided, and BCE technique, which uses pilots and natural constraints to perform the channel estimation. In another way, a number of antennas at the transmitter and receiver increases the complexity of BCE technique. The pilot channel estimation based techniques useful for the slow varying channels. Several types of research presented the S-BCE technique to solve the drawback of pilot and BCE techniques. The S-BCE technique achieves better performance and improve accuracy than pilot/BCE technique [18], [19].

\section{LITERATURE WORK}

Several techniques are suggested by researchers in the channel estimation used for optical OFDM. In this scenario, brief evaluation of some important contributions to the existing literatures are presented.

\begin{tabular}{|l|l|l|l|l|}
\hline \multicolumn{1}{|c|}{ Author } & \multicolumn{1}{|c|}{ Methodology } & \multicolumn{1}{c|}{ Advantage } & \multicolumn{1}{c|}{$\begin{array}{c}\text { Limitation } \\
\text { Performance } \\
\text { measure }\end{array}$} \\
\hline $\begin{array}{l}\text { Wu et al, } \\
\text { [20] }\end{array}$ & $\begin{array}{l}\text { Training symbol used } \\
\text { in the optical signal to } \\
\text { noise ratio }\end{array}$ & $\begin{array}{l}\text { The method does not } \\
\text { require additional } \\
\text { overhead; hence the } \\
\text { spectral efficiency is not } \\
\text { degraded. }\end{array}$ & $\begin{array}{l}\text { This method increased } \\
\text { the power at the same } \\
\text { time monitoring } \\
\text { performance was } \\
\text { degraded }\end{array}$ & $\begin{array}{l}\text { Estimation error, } \\
\text { power value, and } \\
\text { polarization loss }\end{array}$ \\
\hline $\begin{array}{l}\text { Zhao et al, } \\
\text { [21] }\end{array}$ & $\begin{array}{l}\text { New channel } \\
\text { estimation technique } \\
\text { for fast optical OFDM }\end{array}$ & $\begin{array}{l}\text { This method has a very } \\
\text { simple system design } \\
\text { which provides better } \\
\text { accuracy }\end{array}$ & $\begin{array}{l}\text { The system architecture } \\
\text { was more complex } \\
\text { when increasing the } \\
\text { training sequence }\end{array}$ & $\begin{array}{l}\text { Training } \\
\text { performance, bit } \\
\text { error rate }\end{array}$ \\
\hline $\begin{array}{l}\text { Fang et al, } \\
\text { [22] }\end{array}$ & $\begin{array}{l}\text { Time domain ML } \\
\text { channel estimation } \\
\text { technique }\end{array}$ & $\begin{array}{l}\text { This method has better } \\
\text { overhead reduction. } \\
\text { Also, it has enhanced } \\
\text { tolerance against laser } \\
\text { phase noise. }\end{array}$ & $\begin{array}{l}\text { considered only time } \\
\text { domain channel } \\
\text { estimation, which may } \\
\text { not be suitable for the } \\
\text { frequency domain } \\
\text { channel estimation } \\
\text { technique. }\end{array}$ & $\begin{array}{l}\text { Chromatic } \\
\text { dispersion, } \\
\text { polarization } \\
\text { mode dispersion, } \\
\text { and noise level }\end{array}$ \\
\hline Ouyang et & Unbiased channel & This method avoided the & The proposed method & Estimation error \\
\hline
\end{tabular}


Nisha Mary Joseph and Dr. Puttamadappa C

\begin{tabular}{|c|c|c|c|c|}
\hline al, [23] & $\begin{array}{l}\text { estimation based } \\
\text { discrete Fresnel } \\
\text { transform }\end{array}$ & $\begin{array}{l}\text { performance degradation } \\
\text { due to the dispersion } \\
\text { depend on the deviation }\end{array}$ & $\begin{array}{l}\text { was only based on } \\
\text { internal- symbol } \\
\text { frequency domain, not } \\
\text { considered about inter } \\
\text { symbol frequency } \\
\text { domain } \\
\end{array}$ & of system error \\
\hline $\begin{array}{l}\text { Qian et al, } \\
{[24]}\end{array}$ & $\begin{array}{l}\text { Channel estimation } \\
\text { based on zero } \\
\text { correlation code }\end{array}$ & $\begin{array}{l}\text { This method has better } \\
\text { channel estimation and } \\
\text { also it reduce the } \\
\text { computation complexity } \\
\text { compared to LSCE } \\
\text { technique }\end{array}$ & $\begin{array}{l}\text { This method only } \\
\text { concentrated on two } \\
\text { performance parameter } \\
\text { such as MSE and Bit } \\
\text { Error Rate (BER) }\end{array}$ & $\begin{array}{l}\text { MSE, and BER } \\
\text { performance }\end{array}$ \\
\hline $\begin{array}{l}\text { Savaux et } \\
\text { al, [25] }\end{array}$ & $\begin{array}{l}\text { MMSE channel } \\
\text { estimation }\end{array}$ & $\begin{array}{l}\text { This proposed method } \\
\text { reduced the complexity } \\
\text { using a low-rank } \\
\text { approximation }\end{array}$ & $\begin{array}{l}\text { This method achieved } \\
\text { less spectral efficiency } \\
\text { but the BER was high }\end{array}$ & $\begin{array}{l}\text { BER } \\
\text { performance }\end{array}$ \\
\hline $\begin{array}{l}\text { Wu et al, } \\
\text { [26] }\end{array}$ & $\begin{array}{l}\text { LS channel estimation } \\
\text { of optical OFDM } \\
\text { system }\end{array}$ & $\begin{array}{l}\text { This method was } \\
\text { optimized for the pilot } \\
\text { tones and pilot sequence, } \\
\text { hence it achieved less } \\
\text { MSE value }\end{array}$ & $\begin{array}{l}\text { The analytical } \\
\text { calculation was the } \\
\text { main drawback of the } \\
\text { proposed }\end{array}$ & $\begin{array}{l}\text { MSE, and BER } \\
\text { performance }\end{array}$ \\
\hline $\begin{array}{l}\text { Yu et al, } \\
{[27]}\end{array}$ & $\begin{array}{l}\text { Channel estimation } \\
\text { based on an individual } \\
\text { subcarrier in optical } \\
\text { OFDM }\end{array}$ & $\begin{array}{l}\text { This method reduced } \\
\text { the inner part } \\
\text { constellation because it } \\
\text { achieved less complexity }\end{array}$ & $\begin{array}{l}\text { This method was } \\
\text { implemented using } \\
\text { several modules, which } \\
\text { required more area }\end{array}$ & $\begin{array}{l}\text { BER } \\
\text { performance }\end{array}$ \\
\hline $\begin{array}{l}\text { Zhao et al, } \\
\text { [28] }\end{array}$ & $\begin{array}{l}\text { Weighted inter-frame } \\
\text { averaging based } \\
\text { channel estimation }\end{array}$ & $\begin{array}{l}\text { It performed various } \\
\text { launched power value }\end{array}$ & $\begin{array}{l}\text { This method only } \\
\text { concentrated on power } \\
\text { performance }\end{array}$ & $\begin{array}{l}\text { Error vector } \\
\text { magnitude, and } \\
\text { power, estimation } \\
\text { accuracy }\end{array}$ \\
\hline $\begin{array}{l}\text { Zhang et al, } \\
\text { [29] }\end{array}$ & $\begin{array}{l}\text { LSCE technique used } \\
\text { for coherent optical } \\
\text { OFDM }\end{array}$ & $\begin{array}{l}\text { This method has less } \\
\text { complexity because it } \\
\text { provided better } \\
\text { performance in slow } \\
\text { fading channels }\end{array}$ & $\begin{array}{l}\text { If the system speed } \\
\text { increases, it leads to } \\
\text { the performance } \\
\text { degradation in the } \\
\text { LSCE technique }\end{array}$ & $\begin{array}{l}\text { MSE and BER } \\
\text { performance }\end{array}$ \\
\hline $\begin{array}{l}\text { Nhan et al, } \\
{[30]}\end{array}$ & $\begin{array}{l}\text { Sparse preamble } \\
\text { channel estimation used } \\
\text { for Polarization } \\
\text { division multiplexed } \\
\text { coherent OFDM }\end{array}$ & $\begin{array}{l}\text { Sparse channel } \\
\text { estimation achieved less } \\
\text { BER. Hence, that } \\
\text { method improved } \\
\text { significant gain. }\end{array}$ & $\begin{array}{l}\text { The performance of the } \\
\text { system was affected by } \\
\text { the phase noise when } \\
\text { fiber nonlinear signals } \\
\text { were degraded. }\end{array}$ & $\begin{array}{l}\text { BER, and Peak to } \\
\text { Average Power } \\
\text { Ratio (PAPR) }\end{array}$ \\
\hline
\end{tabular}

\section{CONCLUSIONS}

The channel estimation is the most powerful and effective algorithm for optical OFDM based on multiuser-visible light communication system. The channel estimation provides an enormous different technology for providing better retrieval value, which is used in several applications such as telephone, radio, television, and internet. This review paper provides an overview of the channel estimation based optical OFDM system and evaluates the developed technologies in terms of advantage, disadvantage, and performance measure. From this review work, it is found that the phase noise is the major problem which affect the signal over the channel estimation process. To overcome this problem researcher implemented several advanced techniques based on channel estimation for the optical OFDM.

\section{REFERENCES}

[1] Shieh, W., Bao, H. and Tang, Y. Coherent optical OFDM: theory and design. Optics express, 16, 2008, pp. 841-859. 
A Review Based on Channel Estimation for Optical - Orthogonal Frequency Division Multiplexing

[2] Yu, Z., Chen, M., Chen, H., Yi, X., Yang, S. and Xie. S. Blind polarization demultiplexing by constructing a cost function for coherent optical PDM-OFDM. Optics express, 23, 2015, pp. 18511-18517.

[3] Le, S. T., McCarthy, M. E., Suibhne, N. M., Haigh, E., Giacoumidis, P. A., Doran, N. J., Ellis, A. D. and Turitsyn, S. K. Decision-directed-free blind phase noise estimation for CO-OFDM. In Optical Fiber Communications conference and Exhibition (OFC), 2015, pp. 1-3.

[4] Yu, Z., Yi, X., Zhang, J., Zhao, D. and Qiu, K. Experimental demonstration of polarization-dependent loss monitoring and compensation in Stokes space for coherent optical PDM-OFDM. Journal of Lightwave Technology, 32, 2014, pp. 3926-3931.

[5] Liu, Z., Kim, J. Y., Wu, D. S., Richardson, D. J. and Slavík. R., Homodyne OFDM with optical injection locking for carrier recovery. Journal of Lightwave Technology, 33, 2015, pp. 34-41.

[6] Bo, T., Huang, L. and Chan. C., Common phase estimation in coherent OFDM system using image processing technique. IEEE Photonics Technology Letters. 27, 2015, pp. 1597-1600.

[7] Sure, P. and Bhuma. C. M. A survey on OFDM channel estimation techniques based on denoising strategies. Engineering Science and Technology, an International Journal, 20, 2017, pp. 629-636.

[8] Colieri, S., Ergen, M., Puri, A. and Bahai. A. A study of channel estimation in OFDM systems. In Proceedings of 56th IEEE Conference Vehicular Technology, 2, 2002, pp. 894-898.

[9] Ha, Y. and Chung. W. Non-data-aided phase noise suppression scheme for CO-OFDM systems. IEEE Photonics Technology Letters, 25, 2013, pp. 1703-1706.

[10] Tan, T. H., Chang, C. C., Jean, F., Chiang, J. Y. and Lu. Y. C. Joint Channel Estimation and Multi-User Detection for OFDMA Systems Using A Genetic Algorithm with Simulated Annealing-Based Mutation. In Proceedings of IEEE International Conference on Systems, Man, and Cybernetics (SMC), 2013, pp. 162-167.

[11] Wu, J. and Fan, P. A survey on high mobility wireless communications: Challenges, opportunities and solutions. IEEE Access, 4, 2016, pp. 450-476.

[12] Şayli, O., Doğan, H. and Panayirci, E. On channel estimation in DC Biased optical OFDM systems over VLC channels. In Proceedings of IEEE International Conference on Advanced Technologies for Communications (ATC), 2016, pp. 147-151.

[13] Yu, Z., Lou, Y., Chen, M., Chen, H., Yang, S. and Xie, S. Experimental demonstration of channel estimation using image processing in optical direct-detection OFDM. In 25th Conference on Wireless and Optical Communication (WOCC), pp. 1-4, 2016.

[14] Zhang, S., Bai, C. L., Luo, Q. L., Huang, L. and He. F. F. An improved least square channel estimation algorithm for coherent optical OFDM system. Optik-International Journal for Light and Electron Optics, 124, 2013, pp. 5937-5940.

[15] Chen, X. and Jiang, M. Adaptive statistical Bayesian MMSE channel estimation for visible light communication. IEEE Transactions on Signal Processing, 65, 2017, pp. 1287-1299.

[16] Zamani, M., Chen, C., Li, C. and Zhang, Z., A blind channel estimation for $100+\mathrm{Gb} / \mathrm{s}$ optical IM-DD DMT over 100-km SMF in $1550 \mathrm{~nm}$, IEEE Photonics Technology Letters, 26, 2014, pp. 1928-1931. 
[17] Shirmohammadi, M. and Damavandi, M., Blind channel estimation of MIMO-OFDM systems in satellite communication. In Proceedings of IEEE International Conference on Information and Communication Technology Convergence (ICTC), 2015, pp. 704-709.

[18] Nayebi, E. and B. D. Rao. Semi-blind Channel Estimation for Multiuser Massive MIMO Systems. IEEE Transactions on Signal Processing, 66, 2018, pp. 540-553.

[19] Ladaycia, A., Mokraoui, A., Abed-Meraim, K. and Belouchrani, A. Performance Bounds Analysis for Semi-Blind Channel Estimation in MIMO-OFDM Communications Systems. IEEE Transactions on Wireless Communications, 16, 2017, pp. 5925-5938.

[20] Wu, Q., Zhang, L., Li, X., Luo, M., Feng, Z., Zhou, H., Tang, M., Fu, S. and Liu, D. Training Symbol Assisted in-Band OSNR Monitoring Technique for PDM-CO-OFDM System. Journal of Lightwave Technology, 35, 2017, pp. 1551-1556.

[21] Zhao, L., He, J., Zhou, Z., Deng, R. and Chen, L. The Research of Optical Fast OFDM Based on Channel Estimation Algorithm. IEEE Photonics Journal, 8, 2016, pp. 1-5.

[22] Fang, X., Yang, C. and Zhang. F., Time-domain maximum-likelihood channel estimation for PDM CO-OFDM systems. IEEE Photon. Technol. Lett. 25, 2013, pp. 619-622.

[23] Ouyang, X., Dobre, O. A. and Zhao. J. Unbiased channel estimation based on the discrete Fresnel transform for CO-OFDM systems. IEEE Photonics Technology Letters, 29, 2017, pp. 691-694.

[24] Qian, X., Deng, H. and He, H. Joint Synchronization and Channel Estimation of ACOOFDM Systems with Simplified Transceiver. IEEE Photonics Technology Letters, 2018.

[25] Savaux, V., Bader, F. and Louët, Y., A joint MMSE channel and noise variance estimation for OFDM/OQAM modulation. IEEE Transactions on Communications, 63, 2015, pp. 4254-4266.

[26] Wu, L., Cheng, J., Zhang, Z., Dang, J. and Liu, H. Channel estimation for optical-ofdmbased multiuser miso visible light communication. IEEE Photonics Technology Letters, 29, 2016, pp. 1727-1730.

[27] Yu, Z., Lou, Y., Chen, M., Chen, H., Yang, S. and Xie. S., Channel Estimation on Individual Subcarrier Using Image Processing in Optical OFDM System. IEEE Photonics Technology Letters, 28, 2016, pp. 1815-1818.

[28] Zhao, H., Li, J., Zhu, P., Zhang, C., Liu, Y., Zhao, Y., He, Y. and Chen. Z. Weighted inter-frame averaging-based channel estimation for CO-OFDM system. IEEE Photonics Journal, 5, 2013, pp. 7902807-7902807.

[29] Zhang, S, Bai, S., Bai, C., Luo, Q. and Fang, W. An improved channel estimation algorithm for CO-OFDM system and its performance analysis. Optoelectronics Letters, 10, 2014, pp. 140-143.

[30] Nhan, N., Morel, P., Azou, S., Morvan, M., Gravey, P. and Pincemin, E. Sparse preamble design for polarization division multiplexed CO-OFDM/OQAM channel estimation. Journal of Lightwave Technology, 36, 2018, pp. 2737-2745. 